\title{
Prevalence of Giardia infection in households of Giardia cases and risk factors for household transmission
}

\author{
Alison Waldram ${ }^{1,2,3,4^{*}}$ (D), Roberto Vivancos ${ }^{1,4,5}$, Catherine Hartley ${ }^{6}$ and Kenneth Lamden ${ }^{7}$
}

\begin{abstract}
Background: Giardia is a leading but neglected cause of infectious gastroenteritis worldwide and is treatable. There is a substantial burden of undetected Giardia in the UK and for every one case of Giardia reported to national surveillance there are 14 cases in the community. We aimed to ascertain the prevalence of, and risk factors associated with secondary household Giardia infections to assess the burden of infection and inform control measures.
\end{abstract}

Methods: We identified all giardiasis cases notified in nine local authorities in Lancashire between June 2014 and June 2015, and invited their household contacts to submit faecal specimens for Giardia testing and complete a risk factor questionnaire. We estimated the proportion of households with additional Giardia infection. We compared household risk factors between households with and without additional Giardia using Fisher's exact test. We used multivariable logistic regression to identify independent risk factors for additional Giardia infections.

Results: We identified additional Giardia infections in 30\% (27/91) of included households. A total of 41 infections were found from 212 household members, of which 37 were asymptomatic. The majority of infections were assemblage B (57\%) but there were also a high number of mixed infections (20\%). Risk factors significantly associated with additional household infections were; having children under 5 years in the household (odds ratio 42; 95\% confidence intervals 10-178) and the presence of gastrointestinal illness in the household before the onset of the index case (odds ratio 9; $95 \%$ confidence intervals 1.5-48).

Conclusions: Our finding of a high household prevalence of asymptomatic infection has raised the public health question of whether treatment of asymptomatic household contacts may be justified in preventing Giardia re-infection of the index case or in preventing secondary cases and household clusters. We recommend the communication of this risk in household contacts of Giardia and reinforcement of standard hygiene controls.

Keywords: Giardia, Household, Transmission, Assemblage

\section{Background}

Giardia is a leading but neglected cause of infectious gastroenteritis worldwide [1] and is treatable. The flagellated protozoan, Giardia lamblia (syn. G. duodenalis and G. intestinalis) comprises eight genetic "assemblages" (A-H) with only A and B affecting humans. Assemblages A and B can also infect pets, livestock and wild animals showing the potential for zoonotic

\footnotetext{
* Correspondence: alison.waldram@phe.gov.uk

${ }^{1}$ Field Epidemiology Service, Public Health England, Liverpool, UK

${ }^{2}$ Field Epidemiology Training Programme, Public Health England, London, UK Full list of author information is available at the end of the article
}

transmission [2]. The reported prevalence of Giardia in human populations is $4-43 \%$ and $1-7 \%$ in low and high income countries respectively $[3,4]$. Prevalence in the UK has been reported as $1.3 \%$ in asymptomatic children [5], $1.4 \%$ in a general practitioner population and $0.9 \%$ in the general population [6]. Between 3000 and 4000 cases are reported annually in England and Wales [7]. There is a substantial burden of undetected Giardia in the UK and for every one case of Giardia reported to national surveillance there are 14 cases in the community [8]. Corresponding ratios for Campylobacter, Cryptosporidium and Salmonella are 9.3, 8.2 and 4.7 
respectively. The incidence of Giardia in Northwest England increased four-fold following the introduction of the enzyme linked-immunosorbent assay for the detection of parasite antigens in stools [9]. This test has greater sensitivity than microscopy [10] and was applied universally to all stool samples, i.e. no testing criteria were applied, indicating that the majority of cases did not have the commonly accepted exposures for Giardia cases.

Giardia transmission occurs through the ingestion of the infective cyst stage shed in human or animal faeces. The cyst may be present in faecally contaminated water, food or fomites. The clinical disease (giardiasis) typically includes diarrhoea, flatulence, abdominal pain and bloating [11] and weight loss due to malabsorption [12]. Some infections are relapsing due to re-infection from an ongoing source, possibly an asymptomatic household member, or because they are refractory to metronidazole therapy [13]. The clinical picture is altered in high prevalence countries due to partial immunity from repeated exposure. Chronic infection in children may cause failure to thrive [14].

Estimates of the proportion of Giardia infections that are asymptomatic, but which have the potential for transmission of Giardia cysts, varies considerably from 5 to $15 \%$ [15] to $76 \%$ [16]. Without treatment infectivity can continue for months, potentially causing household clusters or outbreaks. There is no evidence based guidance on when to treat asymptomatic infection and when it may curtail transmission, and asymptomatic carriage is generally not treated [17, 18]. However expert opinion suggests treatment of asymptomatic Giardia infection in certain circumstances, for example food handlers, day care nurseries and recurrent infection in a household $[19,20]$.

The aim of this study was to estimate the prevalence of Giardia infection in households of index cases of giardiasis and to identify characteristics of households with more than one case of giardiasis. The study investigated infected rather than diseased cases (defined as symptomatic and therefore more likely to be reported) to provide a more comprehensive insight into transmission dynamics and risk factors within Northwest England households.

\section{Methods}

\section{Prevalence survey}

An observational study was conducted to estimate the prevalence of Giardia infection in households of confirmed Giardia cases in nine local authorities in Lancashire between June 2014 and June 2015. Giardia cases were identified by the detection of Giardia antigen in a stool specimen using a faecal antigen enzyme immunoassay (EIA) method as previously described $[9,10]$, by the three participating hospital laboratories in Lancaster, Blackburn and Preston. All positive specimens were further characterised by assemblage, details of the methods are described [21].

Households were invited to participate by an environmental health officer during their routine public health investigation. All household members were asked to provide a stool sample. A household member was defined pragmatically as a person who lived in the same residence as the case for at least two nights per week in the month prior to diagnosis or had household equivalent contact for example in a care home or university residence. All stool samples were tested using the same EIA method as the index cases. Index cases were excluded if they lived in a single person household.

The prevalence of additional Giardia infection was measured by dividing the number of households that had at least one case of Giardia infection in addition to an index case by the total number of households included in the study. The Giardia prevalence amongst household contacts was also estimated by dividing the total number of additional infections detected by the total number of household contacts.

The sample size was based on an estimated additional Giardia household prevalence of 10\% (local surveillance data showed that a second symptomatic case of Giardia was reported in $7 \%$ of households plus an additional 3\% estimated for asymptomatic individuals). The significance level used was 0.05 (corresponding to 95\% confidence intervals) with a confidence width of 0.05 with an estimated a response rate of $80 \%$ the sample size was 130 households.

\section{Cross-sectional analysis}

We compared households with and without secondary infection to determine the characteristics of households with secondary infections. A "case" household was defined as a household with at least one additional Giardia infection in a household member. A "control" household had no additional Giardia infections. We compared household characteristics between "case" and "control" households using univariable analyses to calculate odds ratios (OR) and $p$ values using Fisher's exact test. The characteristics were identified from the index case study questionnaire and additional assemblage information. We used multivariable logistic regression to identify independent risk factors for additional Giardia infections. All risk factors that had a $p$ value less than 0.2 were considered in a multivariable analysis. The final model included risk factors that were significantly associated with additional Giardia infections i.e. $p$ value $<0.05$.

Questionnaire information was entered using EpiData and data was analysed using Stata v12 (StatCorps). The date of onset for cases was estimated from the in-house 
Public Health England case management system if not available from the questionnaire. The dataset was checked for accuracy using Stata to clean the data and check for impossible values and missing data items were sought via environmental health officers or the in-house case management system.

\section{Results}

\section{Prevalence survey}

The number of index Giardia cases identified was 186 . Of these 17 were excluded as a single person household and 26 could not be contacted, resulting in 143 eligible index cases (Fig. 1). Of these, 91 households participated giving a response rate of $64 \%$. There were no significant differences between households that participated and those that didn't for household size, age or sex of the index case. Within the 91 study households there were 237 household members of whom 212 (89\%) provided a stool sample (Fig. 1).

At least one additional case of Giardia infection was detected in 27 households, giving a household prevalence of 30\% (27/91) (95\% confidence intervals (CI): 20-39\%). Giardia was detected in 41/212 (19\%) of household members of whom 37 (90\%) were asymptomatic, giving a prevalence of asymptomatic infection of
17\% (37/212) (95\% CI: 12-23\%) and a prevalence of undetected symptomatic infection of $2 \%(4 / 212)$ (95\% CI: $0.06-3.7 \%)$. The age groups most affected by asymptomatic infection were $0-4$ and $5-9$, with $51 \%$ and $35 \%$ of household members being affected, respectively (Table 1). The number of additional Giardia positive individuals in a single household ranged from one to five.

\section{Cross-sectional analysis}

The univariable analyses for risk factors when comparing households with additional Giardia infection against those without additional Giardia infection can be seen in Table 2.

The highest association with additional household Giardia infection was with having a child under 5 years old in the household (OR 29; 95\% CI 8-114). There were other risk factors linked to having children; children in nappies in the household (OR 4; 95\% CI 1-18), being involved in changing nappies in the household (OR 3; 95\% CI 0.8-16), being an index case under 5 years old (OR 3; 95\% CI 0.7-11) and children attending nursery in the household (OR 2; 95\% CI 0.6-10). Other characteristics associated with additional infection were related to the number of people and ratio to facilities;

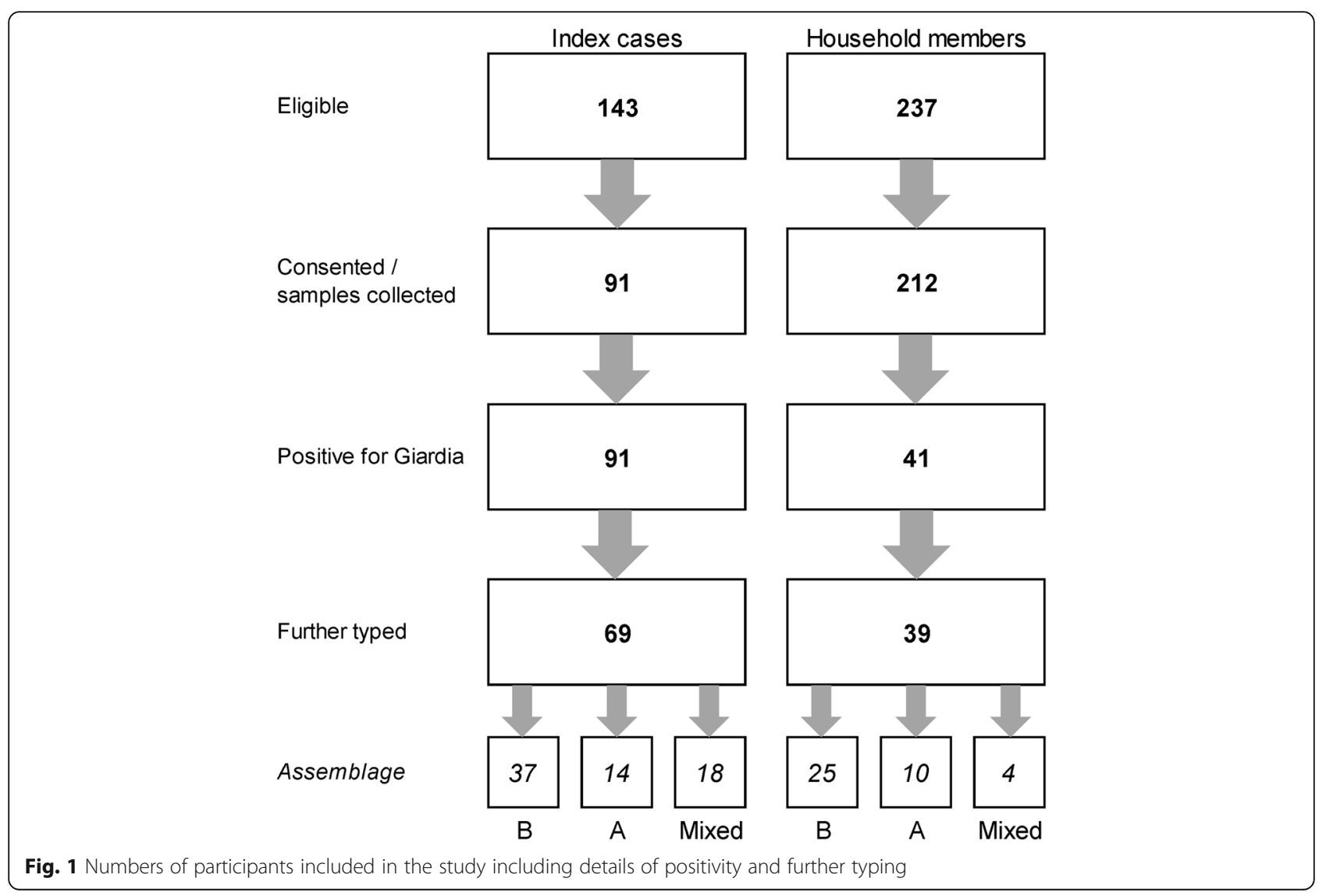


Table 1 Number of household members by asymptomatic infection status and percentage of asymptomatic infection in household members

\begin{tabular}{|c|c|c|c|c|c|c|c|}
\hline \multirow[t]{2}{*}{$\begin{array}{l}\text { Age group of } \\
\text { household members }\end{array}$} & \multicolumn{2}{|c|}{$\begin{array}{l}\text { Asymptomatic infections } \\
\text { in household members }\end{array}$} & \multicolumn{2}{|c|}{$\begin{array}{l}\text { Household members } \\
\text { with no infection }\end{array}$} & \multicolumn{2}{|c|}{$\begin{array}{l}\text { Total household } \\
\text { members }^{\mathrm{a}}\end{array}$} & \multirow{2}{*}{$\begin{array}{l}\text { Percentage of } \\
\text { asymptomatic } \\
\text { infection in } \\
\text { household } \\
\text { members }\end{array}$} \\
\hline & Number & $\%$ & Number & $\%$ & Number & $\%$ & \\
\hline $0-4$ & 19 & 51 & 18 & 12 & 37 & 19 & 51.4 \\
\hline $5-9$ & 8 & 22 & 15 & 10 & 23 & 12 & 34.8 \\
\hline 10-19 & 1 & 3 & 33 & 21 & 34 & 18 & 2.9 \\
\hline 20-29 & 3 & 8 & 13 & 8 & 16 & 8 & 18.8 \\
\hline 30-39 & 4 & 11 & 27 & 18 & 31 & 16 & 12.9 \\
\hline $40-49$ & 1 & 3 & 17 & 11 & 18 & 9 & 5.6 \\
\hline $50+$ & 1 & 3 & 31 & 20 & 32 & 17 & 3.1 \\
\hline Total & 37 & 100 & 154 & 100 & 191 & 100 & 19.4 \\
\hline
\end{tabular}

${ }^{a} 4$ symptomatic household members and 17 household members with no infection and no available age were excluded

having less than one bedroom per person in the household (OR 4; 95\% CI 1-12), having less than one toilet per person in the household (OR 3; 95\% CI 1-14) and having four or more people in the household (OR 3; $95 \%$ CI 1-8). No association was found between having additional Giardia infection in the household and owning a cat (OR 0.3; 95\% CI 0.5-1) and/or dog (OR 0.6: 95\% CI 0.4-2). Of the four index cases with previous Giardia infection (ranging from 3 to 26 months prior to the current infection), none had any additional infection in the household.

In the multivariable analysis two risk factors remained significantly associated with additional Giardia infection in the household; having children under 5 years in the household (OR 42.35; 95\% CI 10.09-177.69) and having anyone with gastrointestinal symptoms in the household in the 3 weeks before the index case (OR 8.55; 95\% CI 1.51-48.28).

Genetic analysis was able to assign an assemblage to $108 / 132$ (82\%) specimens. Of these 62 (57\%) were assemblage B, 24 (20\%) assemblage A and 22 (20\%) were mixed A and B. Three households did not have assemblage typing completed. If the index case in the household had assemblage A, the household was significantly less likely to have any additional infection (OR 0.1; 95\% CI 0-0.8). The assemblage of the index case and the assemblage of the household members were concordant in $92 \%$ of households $(22 / 24)$. This included both single assemblage concordance i.e. A and A or B and B (54\%; $13 / 24$ ) and where there was mixed infection and single assemblages present e.g. A/B and A (38\%; 9/24).

\section{Discussion}

To our knowledge this is the first study of Giardia prevalence amongst household contacts of sporadic Giardia cases. During an outbreak of giardiasis in 1977 no additional cases of Giardia were found in 23 household contacts of eight index cases [15]. In contrast we found a high prevalence of asymptomatic Giardia infection with an additional Giardia infection detected in $30 \%$ of households and $17 \%$ of all household contacts were found to have asymptomatic infection. This high prevalence may fuel transmission in the household and in the community to a greater extent than is currently recognised. Only four additional symptomatic infections were identified however this was a point prevalence and the true rate of symptomatic infection amongst household contacts will be higher and requires evaluation by a longitudinal study of Giardia infected households.

Limitations of this study included the small sample size and the single geographical study area. Further studies would determine whether the findings were generalisable more widely in a low Giardia prevalence setting taking account of Giardia diagnostic methods and environmental and socioeconomic factors, for example household size and type of housing. Although a small study, the sample size was sufficient to provide an estimate of the true prevalence of additional asymptomatic infections. The response rate of $64 \%$ was lower than anticipated although it seems unlikely that the Giardia prevalence in non-responding households would be substantially different to responding households due to the similarity in demographics and risk factors. A potential limitation of the study - poor compliance with stool sampling by asymptomatic household members - did not occur, with a compliance rate of $89 \%$ adding to the strength of the findings.

We found a strong association between the presence of additional Giardia cases and having children aged under 5 years in the household. The transmission of Giardia has been reported frequently in day care or nursery settings previously $[5,22]$ and has been shown to be associated with changing nappies [23]. This result adds to the body of evidence that close contact with 
Table 2 Univariable analyses comparing households with additional Giardia infection to those without

\begin{tabular}{|c|c|c|c|c|c|c|c|c|c|}
\hline \multirow[t]{2}{*}{ Risk factor / characteristic } & \multicolumn{3}{|c|}{$\begin{array}{l}\text { Households with } \\
\text { additional Giardia infection }\end{array}$} & \multicolumn{3}{|c|}{$\begin{array}{l}\text { Households without } \\
\text { additional Giardia infection }\end{array}$} & \multirow[t]{2}{*}{ Odds Ratio } & \multirow[t]{2}{*}{$95 \% \mathrm{Cl}$} & \multirow[t]{2}{*}{$P$ value } \\
\hline & Total & Exposed & $\%$ & Total & Exposed & $\%$ & & & \\
\hline Children $(<5)$ in household & 27 & 21 & 77.8 & 64 & 7 & 10.9 & 28.50 & {$[7.55-113.54]$} & 0.000 \\
\hline Less than 1 bedroom per person in household & 27 & 16 & 59.3 & 64 & 17 & 26.6 & 4.02 & {$[1.41-11.59]$} & 0.004 \\
\hline Assemblage B in the index case & 25 & 24 & 96.0 & 43 & 30 & 69.8 & 10.40 & {$[1.34-459.95]$} & 0.012 \\
\hline Children in nappies in household & 24 & 16 & 66.7 & 22 & 7 & 31.8 & 4.29 & {$[1.07-17.73]$} & 0.038 \\
\hline Less than 1 toilet per person in household & 27 & 23 & 85.2 & 64 & 41 & 64.1 & 3.23 & {$[0.93-14.24]$} & 0.049 \\
\hline Female index case & 27 & 15 & 55.6 & 64 & 21 & 32.8 & 2.56 & {$[0.92-7.13]$} & 0.060 \\
\hline Cat in household & 27 & 3 & 11.1 & 61 & 19 & 31.2 & 0.28 & {$[0.05-1.10]$} & 0.062 \\
\hline 4 or more people in household & 27 & 18 & 66.7 & 64 & 28 & 43.8 & 2.57 & {$[0.92-7.48]$} & 0.066 \\
\hline Involved in changing nappies & 20 & 10 & 50.0 & 22 & 5 & 22.7 & 3.40 & {$[0.76-16.21]$} & 0.107 \\
\hline Assemblage $\mathrm{A}$ in the index case & 25 & 8 & 32.0 & 43 & 23 & 53.5 & 0.41 & {$[0.13-1.28]$} & 0.130 \\
\hline Vomiting in index case & 26 & 16 & 61.5 & 60 & 26 & 43.3 & 2.09 & {$[0.74-6.04]$} & 0.160 \\
\hline Index case under 5 years old & 27 & 6 & 22.2 & 64 & 6 & 9.4 & 2.76 & {$[0.65-11.48]$} & 0.171 \\
\hline Illness in household before index case & 27 & 6 & 22.2 & 59 & 6 & 10.2 & 2.52 & {$[0.59-10.53]$} & 0.181 \\
\hline Children that go to nursery in household & 24 & 13 & 54.2 & 21 & 7 & 33.3 & 2.36 & {$[0.61-9.53]$} & 0.231 \\
\hline Dog/cat in household & 27 & 12 & 44.4 & 64 & 38 & 59.4 & 0.55 & {$[0.20-1.49]$} & 0.250 \\
\hline Duration of illness greater than 7 days & 26 & 26 & 100.0 & 57 & 53 & 93.0 & . & {$[0.48-]$.} & 0.304 \\
\hline Previous Giardia in index case & 27 & 0 & 0.0 & 60 & 4 & 6.7 & 0.00 & {$[0.00-2.10]$} & 0.306 \\
\hline Index case travelled abroad before onset & 27 & 7 & 25.9 & 61 & 22 & 36.1 & 0.62 & {$[0.19-1.85]$} & 0.462 \\
\hline Dog in household & 27 & 12 & 44.4 & 62 & 23 & 37.1 & 1.36 & {$[0.49-3.73]$} & 0.638 \\
\hline Dog in household under 2 years & 18 & 1 & 5.6 & 41 & 5 & 12.2 & 0.42 & {$[0.01-4.28]$} & 0.656 \\
\hline Index case contact with other illness & 26 & 3 & 11.5 & 56 & 4 & 7.1 & 1.70 & {$[0.23-10.85]$} & 0.673 \\
\hline Assemblage $A B$ in the index case & 25 & 7 & 28.0 & 43 & 10 & 23.3 & 1.28 & {$[0.35-4.50]$} & 0.773 \\
\hline Any pet in household & 27 & 16 & 59.3 & 61 & 34 & 55.7 & 1.16 & {$[0.42-3.24]$} & 0.818 \\
\hline White British index case & 27 & 24 & 88.9 & 64 & 57 & 89.1 & 0.98 & {$[0.20-6.38]$} & 1.000 \\
\hline Dog or cat in household under 2 years & 20 & 2 & 10.0 & 48 & 7 & 14.6 & 0.65 & {$[0.06-3.92]$} & 1.000 \\
\hline Index case resident in rural location & 27 & 3 & 11.1 & 64 & 6 & 9.4 & 1.21 & {$[0.18-6.22]$} & 1.000 \\
\hline Diarrhoea in index case & 26 & 25 & 96.2 & 63 & 61 & 96.8 & 0.82 & {$[0.04-50.26]$} & 1.000 \\
\hline Cat in household under 2 years & 13 & 1 & 7.7 & 35 & 2 & 5.7 & 1.38 & {$[0.02-28.53]$} & 1.000 \\
\hline Household is a farm & 26 & 0 & 0.0 & 58 & 1 & 1.7 & 0.00 & {$[0.00-]$.} & 1.000 \\
\hline Household has a garden & 26 & 19 & 73.1 & 59 & 42 & 71.2 & 1.10 & {$[0.36-3.67]$} & 1.000 \\
\hline
\end{tabular}

children, even those without symptoms, can play an important role in the transmission of Giardia.

Developing a 'high risk household' definition may be useful for the communication of risk and advising households on ways of reducing this risk. Household factors such as a greater concentration of individuals and fewer facilities also increased the risk of transmission. This may be related to a higher risk of transmission from a contaminated toilet area in households with proportionately fewer toilet facilities per household member. A larger study powered to investigate this association is required to confirm this finding.

Assemblage typing found that the majority of infections were assemblage $\mathrm{B}$, which has previously been associated with person to person transmission [21, 22]. There were a high percentage of mixed assemblage infections (20\%). The concordance rate of index and secondary household cases has not been previously reported. Two households had discordant assemblages, possibly due to differing sources or a missed mixed infection in the household.

\section{Conclusions}

Our finding of a high household prevalence of asymptomatic infection has raised the public health question of whether treatment of asymptomatic household contacts may be justified in preventing Giardia re-infection of the index case or in preventing household clusters. 
This is particularly pertinent in households containing children under 5 years in which $50 \%$ of household members under 5 years had asymptomatic Giardia infection. Currently, asymptomatic carriage is generally not treated due to lack of evidence, but treatment seems rational in failed treatment of a case or where there is a household cluster. Evidence of the effectiveness of treating asymptomatic infection in curtailing transmission could lead to the offer of routine testing of household contacts or a pragmatic alternative of offering blind treatment to all household contacts. Wider availability of sensitive PCR diagnostic tests may aid a more targeted approach to contact treatment in the future. As this was a prevalence study it cannot provide evidence on the impact of treating asymptomatic infection. A longitudinal study on a larger population is required before recommending any change in current practice.

\section{Abbreviations}

Cl: Confidence interval; EIA: Enzyme immunoassay; HPRU: Health protection research unit; NIHR: National Institute for Health Research; OR: Odds ratio; PHE: Public Health England

\section{Acknowledgements}

The authors would like to acknowledge all participants of the study for their help. We would also like to thank the environmental health teams for undertaking the additional work that the study generated. We thank Professor Jonathan Wastling for supporting the assemblage typing.

\section{Funding}

The study was funded by Cumbria and Lancashire Health Protection Team and the Field Epidemiology Service, Public Health England. This work was supported by the National Institute for Health Research Health Protection Research Unit (NIHR HPRU) in Gastrointestinal Infections and the NIHR HPRU in Emerging and Zoonotic Infections at the University of Liverpool.

\section{Availability of data and materials}

The datasets generated and analysed during the current study are not publicly available due the confidential nature of the information but a redacted dataset can be made available from the corresponding author on reasonable request.

\section{Disclaimer}

The research was funded by the NIHR HPRU in Gastrointestinal Infections and the NIHR HPRU in Emerging and Zoonotic Infections at the University of Liverpool in partnership with Public Health England (PHE), University of East Anglia, University of Oxford and the Institute of Food Research. The views expressed are those of the author(s) and not necessarily those of the NHS, the NIHR, the Department of Health or Public Health England.

\section{Authors' contributions}

AW designed the study, completed the data entry, data analysis and drafted the manuscript. RV and KL were supervisors of this work so contributed to the study design and drafting the manuscript. $\mathrm{CH}$ provided advice, interpretation and conducted all assemblage further typing and assisted with drafting the manuscript. All authors read and approved the final manuscript.

\section{Ethics approval and consent to participate}

Ethical approval was received for this study from NRES Committee North West Lancaster (Reference number: 14NW0151), Public Health England and Veterinary Research Ethics Committee, University of Liverpool (Reference number: VREC228). Participants were informed of the study and the requirements and asked to return a consent form with their laboratory samples.

\section{Consent for publication}

Not applicable.

\section{Competing interests}

The authors declare that they have no competing interests.

\section{Publisher's Note}

Springer Nature remains neutral with regard to jurisdictional claims in published maps and institutional affiliations.

\section{Author details}

${ }^{1}$ Field Epidemiology Service, Public Health England, Liverpool, UK. ${ }^{2}$ Field Epidemiology Training Programme, Public Health England, London, UK. ${ }^{3}$ European Programme for Intervention Epidemiology Training, European Centre for Disease Prevention and Control, Stockholm, Sweden. ${ }^{4} \mathrm{NIHR}$ Health Protection Research Unit in Gastrointestinal Infections, University of Liverpool, Liverpool, UK. ${ }^{5}$ NIHR Health Protection Research Unit in Emerging \& Zoonotic Infections, University of Liverpool, Liverpool, UK. ${ }^{6}$ Department of Infection Biology, Institute of Infection and Global Health, University of Liverpool, Liverpool, UK. ${ }^{7}$ Cumbria and Lancashire Health Protection Team, Public Health England, Preston, UK.

Received: 14 March 2017 Accepted: 3 July 2017

Published online: 11 July 2017

\section{References}

1. Savioli L, Smith H, Thompson A. Giardia and Cryptosporidium join the "Neglected Diseases Initiative". Trends Parasitol. 2006;22:203-8.

2. Ryan U, Cacciò SM. Zoonotic potential of Giardia. Int J Parasitol. 2013;43:943-56

3. Rogawski ET, Bartelt LA, Platts-Mills JA, Seidman JC, Samie A, Havt A, et al. Determinants and Impact of Giardia Infection in the First 2 Years of Life in the MAL-ED Birth Cohort. J Pediatr Infect Dis Soc. 2017;6:153-60.

4. Feng Y, Xiao L. Zoonotic potential and molecular epidemiology of Giardia species and giardiasis. Clin Microbiol Rev. 2011;24:110-40.

5. Davies AP, Campbell B, Evans MR, Bone A, Roche A, Chalmers RM. Asymptomatic carriage of protozoan parasites in children in day care centers in the United kingdom. Pediatr Infect Dis J. 2009:28:838-40.

6. IID Study Group. A Report of the Study of Infectious Intestinal Disease in England Food Standards Agency. 2000. http://www.esds.ac.uk/doc/ 4092\%5Cmrdoc\%5Cpdf\%5C4092userguide6.pdf. Accessed 29 Jul 2015.

7. Public Health England. Giardia: guidance and data. Giardia data 2006 to 2015. https://www.gov.uk/guidance/giardia\#epidemiology. Accessed 23 May 2017.

8. Tam CC, Rodrigues LC, Viviani L, Dodds JP, Evans MR, Hunter PR, et al. Longitudinal study of infectious intestinal disease in the UK (IID2 study): incidence in the community and presenting to general practice. Gut. 2012;61:69-77.

9. Ellam H, Verlander NQ, Lamden K, Cheesbrough JS, Durband CA, James S. Surveillance of giardiasis in Northwest England 1996-2006: impact of an enzyme immunoassay test. Euro Surveill Bull Eur Sur Mal Transm Eur Commun Dis Bull. 2008;13(37):2418-24.

10. McHardy $\mathrm{H}$, Wu M, Shimizu-Cohen R, Couturier MR, Humphries RM Detection of intestinal protozoa in the clinical laboratory. J Clin Microbiol. 2014;52:712-20.

11. Ali SA, Hill DR. Giardia intestinalis. Curr Opin Infect Dis. 2003;16:453-60

12. Nygård K, Schimmer B, Søbstad $\varnothing$, Walde A, Tveit I, Langeland N, et al. A large community outbreak of waterborne giardiasis-delayed detection in a non-endemic urban area. BMC Public Health. 2006:6:141.

13. Nabarro LEB, Lever RA, Armstrong M, Chiodini PL. Increased incidence of nitroimidazole-refractory giardiasis at the Hospital for Tropical Diseases, London: 2008-2013. Clin Microbiol Infect Off Publ Eur Soc Clin Microbiol Infect Dis. 2015:21:791-6.

14. Ignatius R, Gahutu JB, Klotz C, Steininger C, Shyirambere C, Lyng M, et al. High prevalence of Giardia duodenalis Assemblage B infection and association with underweight in Rwandan children. PLoS Negl Trop Dis. 2012;6:e1677.

15. Hill DR. Giardia lamblia. In: Gillespie S, Pearson RD, eds. Principles and Practice of Clinical Parasitology. John Wiley \& Sons Ltd; 2001. P. 219-242.

16. López CE, Dykes AC, Juranek DD, Sinclair SP, Conn JM, Christie RW, et al, Waterborne giardiasis: a communitywide outbreak of disease and a high rate of asymptomatic infection. Am J Epidemiol. 1980;112:495-507. doi:10. 1002/0470842504.ch10.

17. NICE CKS. Gastroenteritis. 2015. https://cks.nice.org.uk/ gastroenteritis\#!scenario:2. Accessed 13 Dec 2016. 
18. Public Health England. Managing suspected infectious diarrhoea. 2015 https://www.gov.uk/government/uploads/system/uploads/attachment_ data/file/409768/Managing_Suspected_Infectious_Diarrhoea_7_CMCN29_ 0115 KB FINAL.pdf. Accessed 13 Dec 2016.

19. Gardner TB, Hill DR. Treatment of Giardiasis. Clin Microbiol Rev. 2001;14:114-28.

20. Katz DE, Taylor DN. Parasitic Infections of the Gastrointestinal tract. Gastroenterol Clin. 2001;30:797-815.

21. Minetti C, Lamden K, Durband C, Cheesbrough J, Fox A, Wastling JM. Determination of Giardia duodenalis assemblages and multi-locus genotypes in patients with sporadic giardiasis from England. Parasit Vectors. 2015;8:444.

22. Pijnacker R, Mughini-Gras L, Heusinkveld M, Roelfsema J, van Pelt W Kortbeek T. Different risk factors for infection with Giardia lamblia assemblages $A$ and $B$ in children attending day-care centres. Eur J Clin Microbiol Infect Dis Off Publ Eur Soc Clin Microbiol. 2016:12:2005-13.

23. Minetti C, Lamden K, Durband C, Cheesbrough J, Platt K, Charlett A, et al. Case-control study of risk factors for sporadic giardiasis and parasite assemblages in North West England. J Clin Microbiol. 2015;10:3133-40.

Submit your next manuscript to BioMed Central and we will help you at every step:

- We accept pre-submission inquiries

- Our selector tool helps you to find the most relevant journal

- We provide round the clock customer support

- Convenient online submission

- Thorough peer review

- Inclusion in PubMed and all major indexing services

- Maximum visibility for your research

Submit your manuscript at www.biomedcentral.com/submit
Biomed Central 